\title{
Pengaruh Spiritualitas terhadap Subjective Well Being Mahasiswa Tingkat Akhir
}

\author{
Nancy Lolo Arung ${ }^{1 a}$, Yonathan Aditya ${ }^{1}$ \\ ${ }^{1}$ Universitas Pelita Harapan, Tangerang, Indonesia \\ a nloloarung@gmail.com
}

\section{The Effect of Spirituality on the Subjective Well Being of Senior Students}

\begin{abstract}
Senior year students who are working on their thesis as one of the requirements to graduate, may experience pressure, which causes stress and depression. A high level of stress and depression in senior year students can lower subjective wellbeing, affecting the thesis's performance. Spirituality can affect the level of subjective well-being of students because with individual spirituality, they can feel God's presence and obtain social support during the difficult times. Hence, this research is conducted to know the effect of spirituality on university students' subjective well-being. This research uses a quantitative method with purposive sampling technique which was conducted to 150 senior year students. The measuring instrument used in this research is SHALOM $(\alpha=.91)$, SPANE $(\alpha=.87$, $\alpha=.78)$ and SWLS $(\alpha=.82)$. The result of this research shows a significant effect between spirituality toward subjective well-being $(\beta=.22, p<.05)$, meaning that the higher the spirituality level of the students, the higher the subjective wellbeing level of that students
\end{abstract}

Manuscript type: Original Research

Article history:

Received: 27 November 2020

Accepted: 2 February 2021

Available online: 04 February 2021
Keywords:

Senior Students

Spirituality

Subjective well-being

\begin{abstract}
Abstrak
Mahasiswa tingkat akhir yang sedang mengerjakan tugas akhir sebagai syarat kelulusan, banyak mengalami tekanan yang mengakibatkan munculnya stres dan depresi. Timbulnya stres dan depresi dalam diri mahasiswa dapat mengakibatkan rendahnya subjective well being sehingga dapat memengaruhi performa pengerjaan tugas akhir. Spiritualitas dianggap dapat memengaruhi tingkat subjective well being mahasiswa, karena dengan spiritualitas individu dapat merasakan kehadiran Tuhan dan mendapatkan social support saat dalam masa sulit. Oleh karena itu, penelitian dilakukan dengan tujuan untuk mengetahui pengaruh spiritualitas terhadap subjective well being mahasiswa. Penelitian dilakukan menggunakan metode kuantitatif, dan menggunakan teknik purposive sampling yang dilakukan pada 150 mahasiswa tingkat akhir. Alat ukur yang digunakan dalam penelitian ini adalah SHALOM $(\alpha=.91)$, SPANE $(\alpha=.87, \alpha=.78)$ dan SWLS $(\alpha=.82)$. Hasil penelitian menunjukkan adanya pengaruh yang signifikan antara spiritualitas terhadap subjective well being $(\beta=.22, \mathrm{p}<.05)$, yang berarti semakin tinggi spiritualitas mahasiswa maka semakin tinggi pula tingkat subjective well being mahasiswa tersebut.
\end{abstract}

Kata Kunci: mahasiswa tingkat akhir; spiritualitas; subjective well being 


\section{PENDAHULUAN}

Pendidikan merupakan salah satu hal yang sangat penting bagi kehidupan manusia, sehingga tak jarang orang tua mengharapkan anaknya untuk menuntut pendidikan hingga ke perguruan tinggi. Di perguruan tinggi, mahasiswa yang sedang mengerjakan tugas akhir atau biasa disebut sebagai mahasiswa tingkat akhir banyak mengalami berbagai tekanan dan kesulitan seperti mencari judul, literatur, waktu yang terbatas, proses revisi yang berulang-ulang, dosen pembimbing yang sulit ditemui atau bahkan ketidakcocokan dengan dosen pembimbing (Cahyani \& Akmal, 2017). Masa ini biasanya membuat mahasiswa menjadi stres hingga depresi. Krisdianto dan Mulyanti (2015) menyebutkan bahwa hasil dari analisis yang dilakukan di Perguruan Tinggi Alma Ata Yogyakarta ditemukan bahwa sebagian besar mahasiswa tingkat akhir mengalami depresi ringan. Penelitian yang dilakukan oleh Hapsari (dalam Abdullah, Sarirah \& Lestari, 2017) juga menemukan sebanyak 45.3\% mahasiswa tingkat akhir mengalami stres saat mengerjakan skripsi. Selain itu dampak dari meningkatnya stres yang dialami mahasiswa dapat membuat mereka dengan sengaja tidak mengerjakan skripsi karena tidak ingin merasa terbebani sehingga lebih memilih mencari kesenangan dari kegiatan lain dan menghindari dosen pembimbing (Gamayanti, Mahardianisa \& Syafei, 2018). Munculnya stres dan depresi dalam diri mahasiswa tingkat akhir juga memengaruhi tingkat kepuasan hidup mahasiswa tingkat akhir tersebut, yang akhirnya akan menurunkan tingkat subjective wellbeing.

Subjective well-being merupakan cara individu mengevaluasi atau menilai kehidupannya berdasarkan evaluasi kognitif dan afektif (Diener et al, 2017). Menurut Compton (2005) subjective well-being merupakan evaluasi seseorang terhadap kehidupannya secara menyeluruh dan tidak didasari atas penilaian dari orang lain. Subjective well-being memiliki tiga dimensi, yakni kepuasan hidup, afek menyenangkan (positive affection), dan afek tidak menyenangkan (negative affection). Kepuasan hidup dapat dimanifestasikan melalui kepuasan kerja, pernikahan, persahabatan, dan lain sebagainya. Adapun afek menyenangkan berarti individu mengalami emosi atau suasana hati yang positif pada umumnya, sedangkan afek tidak menyenangkan berarti individu mengalami emosi atau suasana hati yang tidak menyenangkan relatif sering, seperti kemarahan, kecemasan, ataupun kesedihan.

Beberapa penelitian menemukan bahwa salah satu faktor yang mempengaruhi Subjective well-being adalah spiritualitas. Kim dan Esquivel (2011) menemukan bahwa spiritualitas memiliki pengaruh paling besar terhadap kepuasan hidup individu. Selain itu, Fisher dan Conskun (2013) menjelaskan bahwa hubungan dengan Tuhan dinilai dapat meningkatkan well-being para mahasiswa. Compton (2005) menyebutkan bahwa seseorang yang menganggap spiritualitas sebagai hal yang penting untuk dilakukan ataupun rajin mengikuti kegiatan keagamaan, dapat memiliki well-being yang tinggi. Individu yang memiliki relasi intim dengan Tuhan ataupun dengan orang disekitarnya, dapat membantu meningkatkan afek positif dan kepuasan hidup. Hal-hal ini dinilai secara keseluruhan memiliki efek yang dapat meningkatkan subjective well-being pada mahasiswa. Menurut Fisher (1998) Spiritualitas berfokus kepada kesadaran yang dimiliki individu akan eksistensi, pengalaman pribadi, perasaan, dan kepercayaan yang dapat memberikan suatu nilai kepada kehidupannya. Spiritualitas penting khususnya di Indonesia, karena Indonesia merupakan salah satu negara yang sangat religius (Gallup International, 2016).

Sekalipun berbagai penelitian terdahulu menunjukkan adanya pengaruh signifikan dari spiritualitas ke subjective well-being, alat ukur spiritualitas yang dipakai merupakan alat ukur yang beragam baik secara konseptual maupun validitas. Fisher (2015) dalam ulasannya mengenai berbagai alat ukur spiritualitas menemukan ada hampir 300 alat ukur spiritualitas yang digunakan selama 40 tahun terakhir dan tidak semuanya baik secara konseptual maupun validitas. Oleh karena itu dalam 
penelitian ini akan digunakan alat ukur spiritualitas Spiritual Health and Life-Orientation Measure (SHALOM) yang validitasnya telah terbukti melalui penelitian di berbagai negara. SHALOM juga mengukur spiritualitas secara komprehensif, dalam arti tidak hanya mengukur relasi dengan Tuhan tapi juga relasi dengan diri sendiri, orang lain dan lingkungan, sehingga kaitan antara spritualitas dengan well-being juga bisa ditelaah secara lebih komprehensif (Abhari, Fisher, Kheiltash, \& Nojomi, 2010). Selain itu kaitan antara spiritualitas ke subjective well-being sangat dipengaruhi oleh budaya. Oleh karena itu ada kemungkinan kaitan dua variabel ini di Indonesia akan berbeda dengan hasil penelitian di luar negeri (Saroglou, 2017; Saroglou et al. 2020). Mempertimbangkan hal-hal diatas, maka peneliti melakukan penelitian mengenai pengaruh spiritualitas terhadap subjective wellbeing pada mahasiswa tingkat akhir. Hipotesis yang diajukan oleh peneliti yakni terdapat pengaruh spiritualitas terhadap subjective well-being pada mahasiswa tingkat akhir.

\section{METODE}

\section{Partisipan}

Dalam penelitian ini ada 155 kuesioner yang dibagikan, namun hanya 150 kuesioner yang dapat digunakan karena adanya ketidaklengkapan jawaban pada item-item tertentu saat melakukan pengisian kuesioner oleh responden. Partisipan dalam penelitian ini diambil dari mahasiswa salah satu universitas Kristen di Tangerang yang memenuhi kriteria sebagai berikut: Pertama, subjek penelitian merupakan mahasiswa tingkat akhir yang aktif menempuh pendidikan S1. Kedua, subjek penelitian sedang mengerjakan tugas akhir berupa skripsi/ magang. Ketiga, subjek penelitian merupakan mahasiswa dengan rentang usia 20 hingga 24 tahun. Keempat, subjek penelitian merupakan mahasiswa semester 10. Jumlah partisipan dalam penelitian ini sebanyak 150 partisipan (33 perempuan, 117 laki-laki). Rentang usia dari 20 tahun hingga 24 tahun dan berasal dari berbagai fakultas.

\section{Instrumen}

Peneliti mengukur spiritualitas menggunakan alat ukur Spiritual Health And Life-Orientation Measure (SHALOM) oleh Fisher (2010) yang telah diadaptasi kedalam Bahasa Indonesia oleh Suciani dan Nuraini (2017). SHALOM mempunyai 12 butir pertanyaan dan 4 dimensi, masingmasing dimensi diukur dengan 3 pertanyaan. Subjective well-being diukur menggunakan menggunakan alat ukur SWLS dan SPANE dari Diener (1984). SWLS terdiri dari 5 butir pertanyaan sedangkan SPANE mempunyai 12 butir pertanyaan, 6 butir untuk emosi positip dan 6 butir lainnya untuk emosi negatip. Validitas alat ukur SHALOM $\alpha=.91$, SPANE positif $\alpha=.87$, SPANE negatif $\alpha=.78$ dan SWLS $(\alpha=.82)$.

\section{Prosedur}

Peneliti mengumpulkan data dengan dengan cara menyebarkan kuesioner kepada 150 mahasiswa tingkat akhir di Universitas di Tangerang. Pengumpulan data dilakukan dengan menyebarkan kuesioner hardcopy yang didalamnya terdapat informed consent, instruksi pengisian 
alat ukur, dan alat ukur kedua variabel. Setelah menghitung skor dari masing-masing partisipan, peneliti mengolah data menggunakan Statistical Package for Social Sciences (SPSS) 23.0. Terakhir, peneliti membandingkan hasil yang didapatkan dengan hipotesa diawal penelitian untuk melihat apakah hasil tersebut ditolak atau diterima.

\section{Teknik Analisis}

Penelitian ini menggunakan uji korelasi spearman untuk melihat korelasi antar variabel, dan teknik analisis regresi untuk mengetahui pengaruh spiritualitas terhadap subjective well being partisipan.

\section{ANALISIS DAN HASIL}

Hipotesis dalam penelitian ini adalah terdapat pengaruh yang signifikan pada spiritualitas terhadap subjective well-being mahasiswa tingkat akhir. Hasil uji statistik menunjukkan bahwa spiritualitas berpengaruh secara positif dan signifikan terhadap subjective well being $(\beta=.22, \rho<.05)$. Hal ini menunukkan semakin tinggi spiritualitas seseorang, semakin tinggi pula tingkat subjective well-being. Analisa lanjutan terhadap dimensi dari spiritualitas menemukan bahwa dari empat dimensi spiritualitas hanya dimensi komunal $((\beta=.32, \rho<.05)$ yang berpengaruh secara positif dan signifikan terhadap subjective well-being, dimensi lingkungan memang berpengaruh signifikan tetapi negatif $(\beta=-.26, \rho<.05)$, sedangkan dimensi transenden $((\beta=.05, \rho>.05)$ dan personal $(\beta=.17, \rho>.05)$ tidak mempunyai pengaruh yang signifikan.

\section{DISKUSI}

Penelitian ini dilakukan untuk melihat apakah terdapat pengaruh spiritualitas pada subjective well-being pada mahasiswa tingkat akhir. Dari hasil analisa data menunjukkan bahwa spiritualitas memiliki pengaruh signifikan terhadap subjective well-being. Berdasarkan hal diatas, dapat disimpulkan bahwa hipotesis dalam penelitian ini diterima karena adanya pengaruh yang signifikan secara positif dari hasil data kuantitatif dalam penelitian ini. Menurut Myers (dalam Compton, 2005) individu yang menganggap spiritualitas sebagai hal yang penting, juga memiliki tingkat subjective well-being yang lebih baik. Individu yang memiliki spiritualitas yang tinggi cenderung memiliki makna dan tujuan hidup yang jelas, memiliki dukungan secara emosional dan sosial dari lingkungan sekitar, serta memiliki tingkat self-esteem yang cenderung tinggi pula. Hal ini didukung oleh penelitian yang dilakukan oleh Abdul-Khalek (2007) yang melakukan penelitian pada mahasiswa di Kuwait dan mendapati bahwa semakin tinggi tingkat spiritualitas mahasiswa maka semakin besar pula tingkat kebahagiaan dan kesejahteraan yang dirasakan mahasiswa tersebut dalam hidupnya.

Namun meskipun dalam penelitian ini spiritualitas secara signifikan mempengaruhi subjective well-being pada mahasiswa tingkat akhir, hanya dimensi komunal yang mempunyai pengaruh positip signifikan terhadap subjective well-being, sedangkan dimensi transenden dan individual tidak. Hal ini sesuai dengan tahap perkembangan mahasiswa yang berada dalam tahap emerging adulthood dimana kualitas pertemanan sangat menentukan kebahagiaan hidup mereka (Demir \& Ozdemir, 2010). Selain itu mahasiwa tampaknya belum mempunyai kemampuan mengenal diri dan Tuhannya 64 
dengan cukup baik sehingga pengaruh dari kualitas pertemanan lebih dominan daripada pengaruh dari kualitas relasi dengan Tuhan (Aditya, Sani, Martoyo \& Pramono, 2018; Kate \& Koster, 2017; Saputra, Goei \& Lanawati, 2016).

Dilain pihak pengaruh negatip dan signifikan dari dimensi lingkungan terhadap subjective well-being memang menimbulkan pertanyaan yang membutuhkan penelitian yang lebih mendalam di masa mendatang. Tinggal di negara berkembang dimana kepedulian terhadap lingkungan masih tidak memadai membuat mereka prihatin jika mereka memperhatikan kondisi lingkungan. Hal inilah yang mungkin membuat mereka yang mempunyai relasi yang semakin baik dengan lingkungan semakin tidak sejahtera hidupnya. Hanya saja ini baru dugaan yang memerlukan pembuktian lebih lanjut.

\section{SIMPULAN DAN SARAN}

\section{Simpulan}

Hasil penelitian ini sesuai dengan hipotesis yaitu semakin tinggi spiritualitas mahasiswa tingkat akhir semakin tinggi pula subjective well-being mereka. Hanya saja tidak seperti penelitian di negara lain hanya dimensi komunitas yang mempunyai pengaruh positip signifikan, dimensi transenden dan personal tidak memiliki pengaruh signifikan, dan dimensi lingkungan mempunyai pengaruh signifikan tapi negatip.

\section{Saran Teoretis}

Reponden pada penelitian ini hanya terbatas di kalangan Kristiani oleh karena itu lebih baik jika dilakukan penelitian pada responden yang mempunyai agama lain mengingat agama yang berbeda mungkin mempunyai dinamika yang berbeda. Selain itu peneliti selanjutnya juga bisa melakukan lebih mendalam mengenai kaitan dimensi lingkungan dari spiritualitas yang mempunyai pengaruh negatip terhadap subjective well-being misalnya dengan melakukan analisa kualitatif dan kuantitatif (mixed-method analysis).

\section{Saran Praktis}

Hasil penelitian ini menunjukkan pentingnya kualitas pertemanan dalam meningkatkan subjective well-being oleh karena itu penting bagi para mahasiswa tingkat akhir yang sedang sibuk dalam pengerjaan tugas akhir untuk tidak melupakan pertemanan. Di tengah-tengah kesibukan melakukan tugas-tugas mereka tetap perlu meluangkan waktu untuk memupuk persahabatan.

\section{REFERENSI}

Abdel-Khalek, A. M. (2007). Subjective well-being and religiosity in Egyptian college students. Psychological Reports, 108, 54-58. doi: 10.2466/07.17.PR0.108.1.54-58 
Abdullah, S. A., Sarirah, T., Lestari, S. (2017). Perfeksionisme dan strategi coping: studi pada mahasiswa tingkat akhir. MEDIAPSI. 3(1). 9-16

Abhari, M. B., Fisher, J. W., Kheiltash, A., \& Nojomi, M. (2010). Validation of the Persian version of spiritual well-being questionnaires. Iran J Med Sci, 14(3), 276-285.

Aditya, Yonathan, Riryn Sani, Ihan Martoyo, and Rudy Pramono. (2018). Predicting well-being from different dimensions of religiousness. Proc. of the 3rd International Conference on Psychology in Health, Educational, Social, and Organizational Settings (ICP-HESOS). doi: $10.5220 / 0008590804580463$

Cahyani, Y. E., \& Akmal, S. Z. (2017). Peranan spiritualitas terhadap resiliensi pada mahasiswa yang sedang mengerjakan skripsi. Psikoislamedia: Jurnal Psikologi, 2(1), 32-41

Christyanti, D., Mustami'ah, D., Sulistiani, W. (2010). Hubungan antara Penyesuaian diri terhadap tuntutan akademik dengan kecenderungan stres pada mahasiswa fakultas kedokteran Universitas Hang Tuah Surabaya. INSAN. 12(3). 153-159

Compton, W. C. (2005) Introduction to Positive Psychology. New York: Thomson Wodsworth.

Demir, M., \& Özdemir, M. (2010). Friendship, need satisfaction and happiness. Journal of Happiness Studies: An Interdisciplinary Forum on Subjective Well-Being, 11(2), 243 259. https://doi.org/10.1007/s10902-009-9138-5

Diener, E. (1984). Subjective well-being. Psychological Bulletin. 95(3). 542-575.

Diener, E., Pressman, S. D., Hunter, J., Delgadillo-Chase, D. (2017). If, why, and when subjective well-being influences health, and future needed research. Applied Psychology: Health and well being. 9(2). 133-167. Doi: 10.1111/aphw.12090

Fisher, J. (2010) Development and application of a spiritual well-being questionnaire called SHALOM. Religions, 1. 105-121.

Fisher, J. W., Coskun, M. K. (2013). Investigating spiritual well-being among Islamic divinity and religious education students in Turkey. REJA. 29(3). 21-28

Fraenkel, J. P., Wallen, N. E. (2008). How to design and evaluate research in education. New York: McGraw-Hill Companies, Inc.

Gamayanti, W., Mahardianisa., Syafei, I. (2018). Self disclosure dan tingkat stress pada mahasiswa yang sedang mengerjakan skripsi. PSYMPATHIC : Jurnal Ilmiah Psikologi, 5, 115-130. Doi: $10.15575 /$ psy.v5il.2282

Kate, J.T., Koster, W.D., W.J. 2017. The effect of religiosity on life satisfaction in a secularized context: Assessing the relevance of believing and belonging. Review of Religious Research, 59 (2), pp. 135-55.

Kim, S., \& Esquivel, G, B. (2011). Adolescent spirituality and resilience: Theory, Research, and Educational practices. Psychology in the Schools, 48(7). 
Krisdianto, A. M., \& Mulyanti, M. (2016). Mekanisme koping dengan tingkat depresi pada mahasiswa tingkat akhir. Jurnal Ners dan Kebidanan Indonesia, 3, 71. doi:10.21927/jnki.2015.3(2).71-76

Saputra, A., Goei, Y. A., Lanawati, S. (2016). Hubungan believing dan belonging sebagai dimensi religiusitas dengan lima dimensi well-being pada mahasiswa di tangerang. Jurnal Psikologi Ulayat. 3 (1). 7-17

Saroglou, V. (2017). Culture, personality, and religiosity. In A. T. Church (Ed.), The Praeger handbook of personality across cultures: Culture and characteristic adaptations (pp. 153184). Praeger/ABC-CLIO.

Saroglou, V., Clobert, M., Cohen, A. B., Johnson, K. A., Ladd, K. L., Van Pachterbeke, M., Adamovova, L., Blogowska, J., Brandt, P-Y., Çukur, C. S.Hwang, K-K., Miglietta, A., Motti-Stefanidi, F., Muñoz-García, A., Murken, S., Roussiau, N., \& Tapia Valladares, J. (2020). Believing, bonding, behaving, and belonging: The cognitive, emotional, moral, and social dimensions of religiousness across cultures. Journal of Cross-Cultural Psychology, 51(7-8), 551-575. https://doi.org/10.1177/0022022120946488

Suciani, T., \& Nuraini, T. (2017). Kemampuan spiritualitas dan tingkat stres pasian diabetes melitus di rumah perawatan: studi pendahuluan. Jurnal Keperawatan Indonesia, 20 (2). doi: 10.7454/jki.v20i2.360

Syaiful, I. A., Bahar, R. N. (2018). Peran spiritualitas dan kepuasan hidup terhadap kualitas hidup pada wirausahawan muda. Humanitas, 13, 122-134. doi: 10.26555/humanitas.v13i2.6068.

Pratama, H. (2016). Well-being dalam sudut pandang budaya: sebuah kajian literatur. Conference: Seminar Nasional Psikologi Positif II. 1-10 